\title{
Democracia: un juego para todos
}

y para nadie

Carlos Eduardo Castro A. carlos.castro@estud.usfq.edu.ec
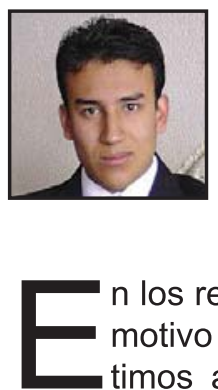

$\mathrm{n}$ los recientes períodos, y con motivo de lo peculiar de los últimos años de política formal en el Ecuador, se ha hecho especial énfasis en los análisis que cuestionan la capacidad de los gobiernos de turno para ser verídicos facultadores de la democracia en el país. Sin embargo, muy poco se ha dicho sobre la calidad política que podrían presentar los ciudadanos ecuatorianos al momento de ser identificados como efectivos ciudadanos de un sistema democrático.

Si nos apegamos al sentido más fundacional de la democracia, encontramos el planteamiento de un sistema que busca coordinar de forma inclusiva las realidades e intereses de las esferas pública y privada, con la finalidad de alcanzar la construcción de un ambiente de convivencia coherente al interior de un determinado espacio social. [1] Dentro de éste marco, el sistema democrático surge como un planteamiento político que busca instaurar un bien generalizado mediante la participación activa de los individuos del conglomerado social, otorgándoles el derecho a voz y voto al momento de traducir de forma bidireccional las necesidades privadas en necesidades públicas, y viceversa.

Para esto la democracia presenta instituciones basadas en derechos de propiedad, una población instruida, la ley como una garantía imparcial y una economía de prosperidad y riqueza. [2] Si bien ambas esferas de la sociedad, pública y privada, son parte necesaria

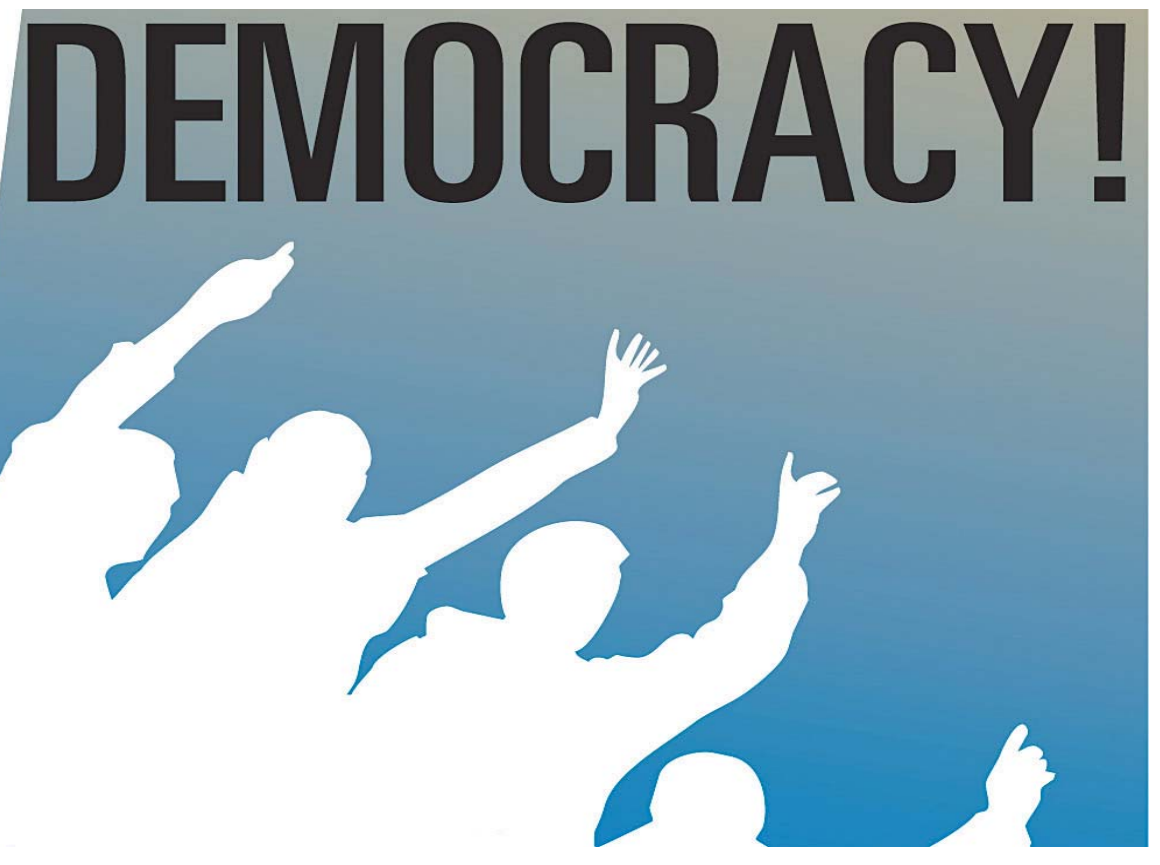

https://camsed.files.wordpress.com/2012/04/democracy.jpeg

para la realización democrática, encontramos que de forma práctica la esfera pública se presenta como un constructo un tanto abstracto, ya que se fundamenta sobre la agrupación y participación efectivas de los individuos de una polis. Por tanto, lo público es fundamentalmente el reflejo de la suma de la realidad privada e individual. A este punto cabe destacar que ni el gobierno ni sus instituciones son tan fundamentales para una verdadera democracia como lo es la ciudadanía. Hoy por hoy, las democracias del mundo apuntan a conseguir el carácter de representativas y participativas, por tanto y tomando en cuenta la importancia del individuo y la esfera privada, cabe poner en cuestionamiento el carácter de quienes son los participantes dentro de la democracia ecuatoriana.

"De acuerdo a Antonio Delhumeau, (...), la democracia es la técnica de organización social que parte de la libertad, respeto y unidad de los indi- viduos para poder organizarse de forma en que todos participen y aporten sus opiniones para un bien común en un ambiente donde haya cultura política y conciencia." [2] Desgraciadamente, en un país donde queda todo por hacer dentro de la esfera relativa a la educación en todos sus niveles, el exigir una conciencia política fundamentada en el conocimiento es una ilusión un tanto lejana. Las condiciones sociales presentes en el país han exigido a la democracia, con el fin de garantizar su supervivencia como sistema político válido, profundos cambios y transformaciones. Las mencionadas exigencias, de una u otra manera, no han hecho más que minar "las exigencias básicas de cualquier sociedad que merezca ser calificada como democrática." [3]

Reflejo de estas circunstancias es el sistema de representación ecuatoriano, cuyas bases estructurales e institucionales han ido en detrimento de 
sus ideales debido al uso recurrente de estrategias de corte populista y clientelar. Para encontrar evidencia de ésta realidad solo basta darle un vistazo a lo que fue el preámbulo a las elecciones presidenciales del presente año. Dicho proceso en múltiples ocasiones no se presentó más que como una subasta de ofertas en torno al tan discutido Bono de Desarrollo Humano, en lugar de mostrarse como el ideal espacio de exposición de ideas dirigidas hacia la gobernabilidad del país.

En el Ecuador se vive un ambiente social en el que la gran mayoría se encuentra compuesta por sectores que guardan necesidades primordiales, inmediatas y tangibles: seguridad, servicios básicos, salud, vivienda etc. Por tanto, estos bloques sociales demandan a toda costa la satisfacción de sus problemas de vida de forma inmediata, sin importar el modo o la personalidad ejecutora. Dentro de ésta realidad ciudadana no cabe en lo absoluto la discusión sobre temas como el respeto a la institucionalidad o cuanta efectividad ostentan determinados candidatos para representar a la población ecuatoriana. Al interior de nuestro país, existe una amplia distancia entre las promesas tradicionales de la democracia y las realidades presentes. La efectividad de las promesas de abundancia, justicia, equidad nos resultan altamente cuestionables. Esto fomenta un sentimiento profundo de insatisfacción frente a la política sistemática.

Sumado a esto, la sociedad ecuatoriana no ha logrado escapar al superlativo carácter individualizador que ha generado la modernidad sobre las

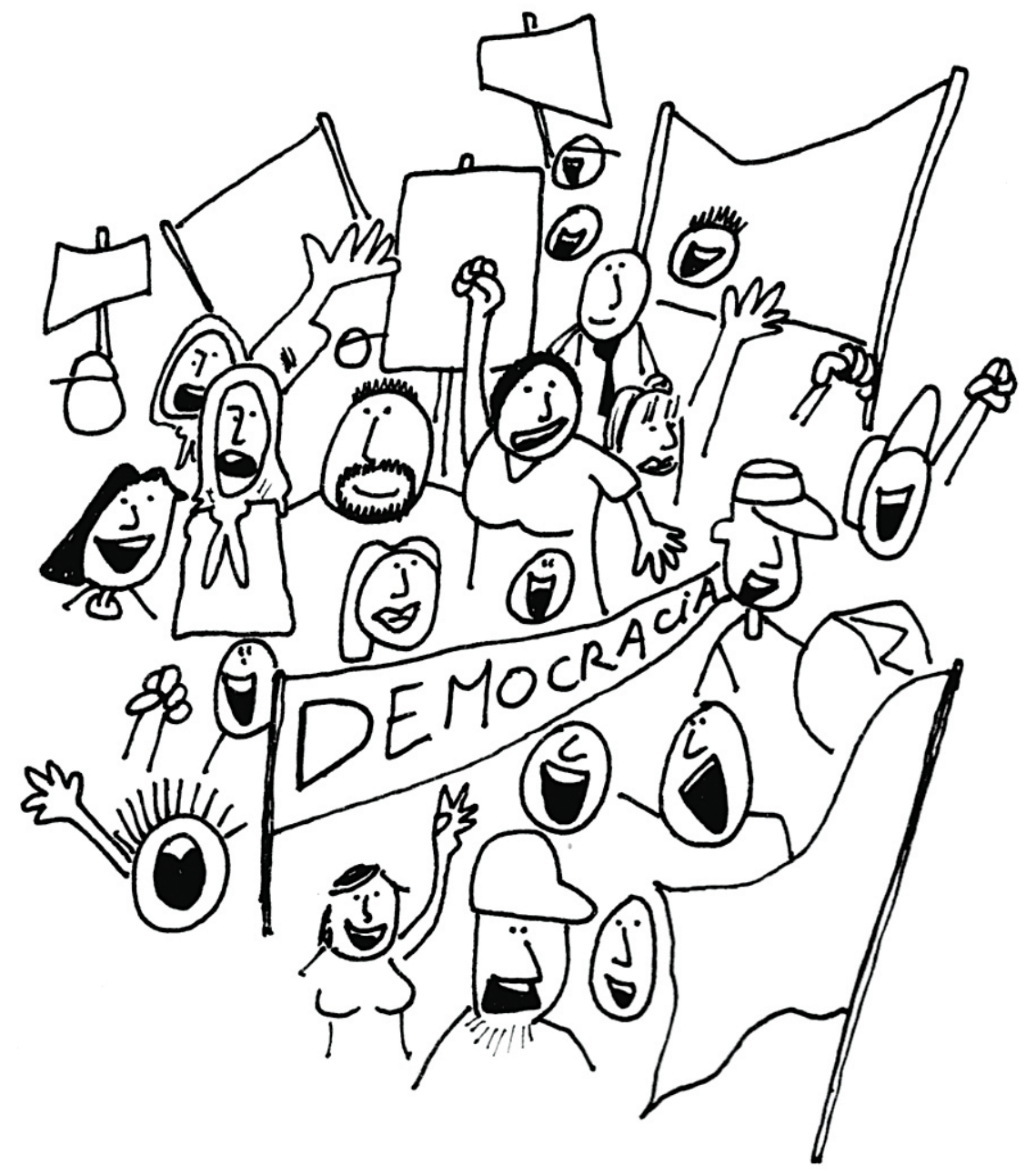

Fuentes consultadas

[1] Bauman, Z. 2011. Daños Colaterales. México: Fondo de Cultura Económica.

[2] Sartori, G. (s.f.). Obtenido de Que es la democracia?: http://catarina.udlap.mx/u_dl_a/tales/documentos/Iri/ martinez_v_ak/capitulo1.pdf

[3] Greppi, A. 2006. Concepciones de la democracia en el pensamiento político contemporáneo. Madrid: Trotta.

[4] Bauman, Z. 2010. Identidad. Buenos Aires: Losada.

[5]Gómez, J. L. 2011. La modernidad latinoamericana insatisfecha. Saarbrucken.: Editorial Académica Española.

[6] Herrera, M., \& Castillo, J. 2004. Sociedades Complejas. Madrid: Ariel. 